that might have been taken to endorse a particular political stance. He can hardly be held culpable for that.

I hope sincerely that the new Health Education Authority will be able to establish its rightul independence and skill in health promotion, but health policy is the responsibility of the health departments, not of the Health Education Authority. The independence of the new authority must be shown in its freedom to promote as it thinks best the aims of the health policy that the departments should formulate clearly and for which they should provide adequate resources. Both these things have yet to be done.

Meanwhile, as a private person, I was able to obtain a copy of The Health Divide by writing for it, and I hope others who are interested will do the same.

GEORGE GODBER

Cambridge CB1 4NZ

Sir,-Since Disraeli's time there has been discussion about two nations in Britain, and in an election year opponents of the government have inevitably increased the frequency and voracity of argument about the inequalities in society. True to form, the leading article by Drs Stephen Lock and Richard Smith (4 April, p 857) again used the $B M F$ to voice a sweeping condemnation of government policy and how this relates to health. But what is the basis of such comment?

Certainly, the health of any society is related to socioeconomic deprivation, and the Black report in 1980 confirmed this. It is therefore clear to all who are interested in the nation's health and welfare that to make any lasting impression on the general wellbeing of our society we need to improve the socioeconomic climate of the country. If any government can do this in the teeth of a recession it should be congratulated.

Drs Lock and Smith imply that the country's health has declined recently, but the fact that there has been greater benefit in some sections of society than in others belies the point that the health of the whole nation has improved under the present government, as has the socioeconomic state of the country. As Drs Lock and Smith mention, there has been increasing spending on the National Health Service. Their argument therefore revolves around the failure of the government to remodel the NHS on that of Finland. This could prove to be an interesting debate, but it is hardly a big stick with which to beat the government.

The only certain way to improve the NHS is to encourage national economic grawth. Improvement in health will follow as night follows day. If we wish to take the long view our path must lead down the road of economic recovery.

F MCKENNA

St James's University Hospital

Leeds LS9 7TF

What contribution has cardiac surgery made to the decline in mortality from coronary heart disease?

SIR,-In his letter about our paper $\operatorname{Dr} \mathbf{R}$ Beaglehole (4 April, p 905) again makes the major error of using a totally inappropriate trial, the European trial, ${ }^{1}$ to estimate the contribution of coronary artery surgery to the decline in mortality from coronary heart disease. The European trial specifically excluded patients "who did not require surgery for relief of symptoms," and consequently patients with severe, intractable angina, the very patients who are usually recommended to undergo surgery, were not included. Furthermore, in this trial $22 \%$ of the randomised "medical" treatment group underwent surgery when they developed severe symptoms.

Because of the association between major symptoms of angina and mortality we were careful to use studies of comparable populations with either major symptoms or strongly positive results of exercise tests. Studies of exercise testing confirm that patients with severe symptoms of angina continue to have a poor prognosis. ${ }^{24}$ Data from the recent coronary artery surgery study, showing a $5 \cdot 4 \%$ annual mortality for patients treated medically ( $58 \%$ subsequently required surgery), ${ }^{5}$ gave us a lower limit of prediction of the contribution of surgery to the fall in mortality of $26 \%$. We think that this figure can be accepted with confidence. It does not in any way argue against the importance of primary prevention in decreasing mortality from coronary heart disease.

HARVEY WHITE

Cardiology Department,

Green Lane Hospital,

Auckland

New Zealand

European Coronary Surgery Study Group. Long term results of prospective randomised study of coronary artery bypass surgery in stable angina pectoris. Lancet 1982;ii: 1173-80.

2 Bruce RA, De Rouen TA, Hammermeister KE. Criteria fo enhanced survival after CABG. Circulation 1979;60:638-46.

3 McNeer JF, Margolis JR, Lee KL, et al. The role of the exercise test in the evaluation of patients for ischaemic heart disease. Circulation 1978;57:64-70.

4 Dagenais GR, Rouleau JR, Christen A, Fabia J. Survival of patients with a strongly positive exercise electrocardiogram. Circulation 1982;65:452-6.

5 Mock MB, Ringqvist I, Fisher LD, et al. Survival of medically treated patients in the coronary artery surgery study (Cass) registry. Circulution 1982;66:562-8.

\section{Long term urethral catheterisation in the} elderly

SIR,-Mr R B Kinder (28 March, p 792) states that "Retention of urine and severe bladder outflow obstruction are best treated by an endoscopic operation, which is rarely contraindicated with current anaesthetic techniques." As urologists, we would have agreed with $\mathrm{Mr} \mathrm{Kinder}$ - until, that is, we recently reviewed the management and outcome of all patients with acute retention at this hospital.

Using the Hospital Activity Analysis records and having excluded those with blocked catheters and inaccurate diagnoses, we identified 81 men who had painful acute retention recorded as their presenting complaint or during their admission in 1985. Forty one (mean age 72) required endoscopic surgery (with no hospital mortality); 20 voided after the catheter was removed and had no further problems (mean follow up 18 months); and of the remaining 19, 17 (mean age 79) had bladder outflow obstruction but were deemed not fit for surgery and treated with long term urethral catheters. Fourteen of these patients $(82 \%)$ were dead within a year (mean survival seven months).

This raises several questions. Was the excess mortality related to a complication of the catheter, or is there a significant population of very elderly patients who can truly be recognised as unfit and have such a poor prognosis that surgery is contraindicated? There is no evidence in the notes of our patients to suggest septicaemia or other causes of death related to the catheter, but our review was a retrospective assessment and thus incomplete.

Interestingly, just over half of these patients were never referred to a urologist and were managed by geriatricians or occasionally by general surgeons. Do geriatricians in other hospitals have a similar population of unfit patients with true urinary retention, and is their prognosis as bad as our figures suggest? Perhaps in $\mathrm{Mr}$ Kinder's experience, as in our own, many of these patients do not get referred and his optimism for curing all obstructive uropathies in such an elderly population is founded on a preselected group of fairly fit elderly patients.

\section{STEPHEN E A ATTWOOD}

KENNETH T H MOORE

Department of Urology,

Northern General Hospital,

Sheffield S5 7AU

\section{Indigenous strongyloidiasis in Nottingham}

SIR,-We were intrigued to read the report by $\mathrm{Dr}$ Veronica Sprott and colleagues of strongyloidiasis in Nottingham (21 March, p 741). Our hospital has been screening ex-prisoners of war from the Far East for this organism since 1978, and, having examined more than 1500 patients, we have a larger series than any yet published. The Liverpool experience reported a $13 \%$ carriage rate of Strongyloides stercoralis in ex-prisoners of war from the Far East, ${ }^{1}$ but our patients seem to have a far lower rate. This led us to examine carefully our diagnostic criteria for this nematode infestation.

One important feature is the history. Diarrhoea, often intermittent and associated with prolonged mild malaise, is typical, often with a history of negative results on investigation. A history of the pathognomonic itchy skin rash of larvae currens is rarely volunteered, even by ex-prisoners of war, but is found to be quite common when patients are questioned, and it would be interesting to know if the patient described by Dr Sprott and coworkers had this.

Unless the rash is present examination is not helpful, and the following investigations are done at Woolwich: absolute eosinophil count, three fresh stool examinations, a duodenal string test for rhabditidiform larvae, and an estimation of IgE concentration. Patients are treated with thiabendazole if any of these investigations yield abnormal results (unless they have an eosinophilia for some other reason), but only definite identification of larvae is conclusive. Eosinophilia is by no means always present in patients with proved strongyloides infestation. ${ }^{2}$

We have been storing serum for serological testing but have no experience of this as yet. How this young lady came by her worms is mysterious, but all physicians and pathologists should be aware of this wily nematode.

KEVIN JONES Nigel CUMBERLAND

Queen Elizabeth Military Hospital,

Woolwich SE18 4QH

Gill GV, Bell DR. Longstanding tropical infections amongst former war prisoners of the Japanese. Lancet 1982;i:958-9.

2 Gill GV, Bell DR. Strongyloides stercoralis infection in former Far East prisoners of war. Br Med J 1979;ii:572-4.

\section{Portraits from Memory: 7-Dr E C}

\section{(Ted) Smith}

SIR,-Sir James Howie's portraits make very interesting and enjoyable reading, especially for those of us who served in the tropics with the armed services or in other capacities. There is, however, some inaccuracy in the paragraph on Dr Ted Smith's version of the saga of yellow fever (21 February, p 501).

Noguchi did not perform a postmortem examination on Stokes. In fact, Stokes died on 19 September 1927 in Lagos and Noguchi died in 